\title{
Sentidos atribuídos por profissionais à promoção da saúde do adolescente
}

\author{
The meaning that health professionals attribute \\ to promotion of the health of adolescents
}

Antonía Alizandra Gomes dos Santos ${ }^{1}$

Raimunda Magalhães da Silva ${ }^{2}$

Maria de Fátima Antero Sousa Machado ${ }^{1}$

Luiza Jane Eyre de Souza Vieira ${ }^{2}$

Ana Maria Fontenelle Catrib ${ }^{2}$

Herla Maria Furtado Jorge ${ }^{2}$

${ }^{1}$ Departamento de Saúde, Centro de Ciências da Saúde, Universidade Regional do Cariri. Rua Cel. Antonio Luis 1161, Pimenta. 63105-000 Crato CE. alizandragomes@ig.com.br ${ }^{2}$ Departamento de Saúde Coletiva, Centro de Ciências da Saúde, Universidade de Fortaleza.

\begin{abstract}
This article analyzes the meanings attributed to practices that promote adolescent health by 47 professionals from the Family Health Program in Fortaleza in the State of Ceará. It is a qualitative study in which semi-structured interviews enabled the production of data, subsequently organized according to content analysis, resulting in the following core themes: promoting health associated with injury prevention; limitation of health promotion to the school environment; the lack of health promotion for adolescents in the healthcare service; and partnerships as a viable way of promoting health for adolescents. The health promotion actions were developed in a timely manner and mostly in the pre-natal, family planning, and cancer prevention programs. The health professionals found the school environment to be an important and viable place for a partnership for health promotion actions for adolescents. There was evidence, albeit incipient, of the health professionals' desire to reorient this practice in the healthcare service.
\end{abstract}

Key words Promoting health, Adolescent, Family health strategy, Health professional
Resumo Este artigo aborda os sentidos atribuidos às práticas de promoção da saúde do adolescente por 47 profissionais da Estratégia Saúde da Família de Fortaleza-Ceará. Trata-se de pesquisa qualitativa em que a entrevista semiestruturada possibilitou a produção dos dados, organizados posteriormente de acordo com a análise de conteúdo, resultando nas temáticas: a promoção da saúde associada à prevenção de agravos; a redução da promoção da saúde ao espaço escolar; a ausência da promoção da saúde para o adolescente no serviço; e a parceria como caminho da viabilização da promoção da saúde do adolescente. As ações de promoção da saúde foram desenvolvidas de forma contingente e na maioria das vezes nos programas de pré-natal, planejamento familiar e prevenção do câncer. Expressou-se que a escola é destacada pelos profissionais como um espaço de parceria para viabilizar as ações de promoção da saúde para os adolescentes. Evidenciou-se, embora de modo incipiente, a vontade de profissionais em reorientar esta prática nos serviços de saúde.

Palavras-chave Promoção da saúde, Adolescente, Estratégia saúde da família, Profissional de saúde 


\section{Introdução}

Ao se discutir a promoção da saúde, não se pode desconsiderar princípios políticos que norteiam à temática. Os eixos estruturantes desses princípios podem ser vistos na Carta de Ottawa, na Política de Promoção da Saúde ${ }^{1}$, que reafirma a busca da qualidade de vida e a redução das vulnerabilidades e dos riscos à saúde, relacionados aos seus determinantes e condicionantes. A promoção da saúde está definida como o processo que permite às pessoas adquirir maior controle sobre sua saúde por meio de conhecimentos, atitudes e comportamentos favoráveis à manutenção e aquisição dela ${ }^{2}$ em diferentes enfoques teóricos e práticos.

Para Cerqueira ${ }^{3}$, a promoção da saúde é um campo de ação amplo que exige o envolvimento da população para que esta incorpore estilos de vida saudáveis e melhore as ações de autocuidado. Ainda que esses preceitos políticos sirvam para ações voltadas para as pessoas em geral, faz-se necessário focalizar grupos ou segmentos que, além de suas especificidades, podem ser vistos como mais vulneráveis a condições adversas à saúde.

Desde essa perspectiva, promover a saúde de adolescentes exige o desafio da adoção de estratégias mais eficazes de participação. Campos ${ }^{4}$ considera o adolescente um grupo-chave para qualquer processo de transformação social. Seu potencial crítico, criativo, inovador e participativo, quando adequadamente canalizado, pode ser o propulsor de mudanças positivas.

Em contraposição, a literatura aponta o adolescente como um grupo vulnerável ao envolvimento com a drogadição, a violência e a gravidez não planejada, bem como agravos específicos ${ }^{5-7}$, dentre outras situações que demandam ações promotoras de saúde.

Para que seja possível articular os princípios da promoção da saúde voltados para adolescentes, ainda se faz necessário explorar a literatura sobre o assunto, principalmente aquela que se encontra em bases de indexação.

Com efeito, fazendo uma revisão não sistematizada, em 10 de fevereiro de 2011, usando os descritores adolescente e promoção da saúde, no SciELO, foram encontrados 37 artigos que discutiam esta temática direcionada para agravos específicos e dimensões pontuais inseridas na política de promoção da saúde. Ao se analisar, porém, os títulos e os resumos destes artigos, não foi encontrada referência sobre saberes e práticas do profissional de saúde, no contexto da promoção da saúde do adolescente, constituindo, desse modo, uma lacuna na elaboração deste conhecimento.

Esta lacuna suscita estudos na temática, com vistas a contribuir com a reorientação dos serviços de saúde considerando que o profissional no exercício de suas funções, assistenciais ou gestoras, responde por atribuições de implementar as políticas públicas de saúde.

Observa-se que, apesar de a atenção à saúde do adolescente constituir uma política específica, a Política Nacional de Atenção à Saúde dos Adolescentes $(\mathrm{PROSAD})^{8}$, a atenção dispensada a este grupo etário continua fragmentada, apresentando fortes evidências de práticas voltadas para o assistencialismo, que se opõem às concepções promotoras de saúde.

Esta fragmentação, entretanto, poderá ser superada, quando se leva em conta a Estratégia da Saúde da Família (ESF) que atende a família como linha de cuidado em seu ciclo vital, podendo assim privilegiar a saúde do adolescente inserida nas práticas de promoção da saúde desenvolvidas pelos profissionais.

Nessa estratégia, a atuação dos profissionais de saúde tem suas ações centradas na tríade promoção, prevenção e assistência, sendo as duas primeiras de maior relevância no processo de cuidar/cuidado, que vai ao encontro dos princípios e diretrizes do Sistema Único de Saúde. Norteado pelas recomendações da ESF, este estudo analisa os sentidos atribuídos às práticas de promoção à saúde do adolescente por profissionais da Estratégia Saúde da Família.

Com suporte nesses questionamentos, nesse objetivo, destacam-se as seguintes indagações: quais os sentidos atribuídos pelos profissionais à promoção da saúde do adolescente? Quais são as lógicas estruturantes das diferenças e das facilidades para se realizar a promoção da saúde com este grupo?

A partir desses questionamentos, adotou-se como marco teórico conceitual da promoção da saúde o mecanismo de fortalecimento e implantação de uma política transversal, integrada e intersetorial, que faça dialogar as diversas áreas dos setores público e privado e da sociedade, compondo redes de compromisso e corresponsabilidade quanto à qualidade de vida da população em que todos sejam partícipes na promoção e no cuidado com a vida ${ }^{1,2,9}$. 
Trata-se de um estudo com abordagem qualitativa ${ }^{10}$, por se compreender a realidade da atuação dos profissionais de saúde no mundo das relações e dos sentidos atribuídos à promoção da saúde com adolescentes, procurando não apenas discutir a temática recorrendo à literatura especializada, mas também utilizar, contrapondo-se a essa discussão, o trabalho realizado num campo empírico.

O panorama de estudo foi o Município de Fortaleza, Ceará, que se encontra dividido em seis regiões administrativas, geridas pelas secretarias regionais de saúde (SER). Esta divisão teve como propósito facilitar a gestão e o acesso da população aos serviços prestados pelo Município ${ }^{11}$.

Nesta pesquisa, optou-se pela área de abrangência da SER VI, constituída por 27 bairros, pois reflete um perfil socioeconômico dicotômico ao conviver com sítios nobres e privilegiados e outros desprovidos dos recursos mínimos necessários à sobrevivência humana e desfrute de qualidade de vida ${ }^{11}$.

Este território (SER VI) agrupa 20 unidades de saúde com 315 equipes distribuídas na ESF, correspondendo a $43 \%$ de cobertura da população do Município, inferior à do Estado que, em 2006, atingia $65 \%{ }^{12}$.

O critério de seleção desta secretaria regional deu-se em função de atender à pactuação político-administrativa entre a Secretaria Municipal de Saúde e a Universidade de Fortaleza, constituindo-se campo de investigação e formação acadêmica $^{13}$. Em relação às unidades investigadas, consideraram-se: as localizadas em realidades diversas, com maior demanda de usuários e com equipes completas de profissionais contratados há mais de um ano.

Atendendo a estes critérios, foram incluídas dez equipes de saúde, com a participação de 47 profissionais, sendo cinco gestores municipais de saúde (secretário municipal, coordenador da Secretaria Executiva VI e os coordenadores da ESF, de Saúde Bucal e da Atenção a Saúde da Criança e Adolescentes), 22 enfermeiros, 11 médicos e nove cirurgiões-dentistas.

Utilizou-se a expressão gestores para designar as funções de secretários de saúde e coordenadores, uma vez que são agentes sociais que executam, direta ou indiretamente, as atividades da gestão do sistema de saúde do Município, em consonância com as diretrizes operacionais do SUS ${ }^{14}$.

A entrevista semiestruturada originou a produção dos dados e contemplou questões relacio- nadas às práticas e saberes sobre promoção da saúde, ocorrendo de junho a agosto de 2010 em salas de atendimentos e na sala destinada à gestão, em horários posteriores aos atendimentos da clientela. Importante é referir que todos os participantes agendaram previamente os encontros e assinaram o termo de consentimento livre e esclarecido.

De posse dos dados não estruturados, procedeu-se a leitura e o agrupamento do material seguindo as orientações da análise de conteúdo, na modalidade temática ${ }^{10,15,16}$. Inicialmente, fezse uma leitura compreensiva das respostas às questões da entrevista e buscou-se identificar os núcleos de sentidos subjacentes a essas respostas. Com origem nesses núcleos, foram constituídas temáticas para a discussão dos resultados da pesquisa as quais foram interpretadas à luz do referencial da promoção da saúde, observando os cinco campos descritos na Carta de Ottawa ${ }^{17}$ - elaboração e implementação de políticas públicas saudáveis, criação de ambientes favoráveis à saúde, reforço da ação comunitária, desenvolvimento de habilidades pessoais e reorientação do sistema de saúde.

O estudo cumpriu os requisitos da Resolução No. 196/96, do Conselho Nacional de Saúde/ Ministério da Saúde ${ }^{18}$, tendo sido aprovado pelo Comitê de Ética em Pesquisa com Seres Humanos da Universidade de Fortaleza.

\section{Resultados}

Entre os 47 participantes do estudo, 35 eram do sexo feminino, enquanto a faixa etária variou de 27 a 58 anos, com predomínio de 30 aos 39 e a média de 35 anos. Relativamente à formação, 26 eram especialistas em Saúde da Família, quatro médicos tinham residência e quatro profissionais concluíram mestrado. O tempo de formação variou de quatro a 34 anos, sendo que 28 profissionais tinham menos de dez anos de formados. Relevante é mencionar que nenhum participante referiu ter formação específica na área da saúde do adolescente. Todos eram concursados para atender na atenção básica no Município de Fortaleza, com jornada de trabalho de 40 horas semanais. Este perfil vai ao encontro de estudos envolvendo profissionais de saúde da atenção básica ${ }^{19}$ que confere uma equipe de adulto jovem, cuja tendência da feminilização desta força de trabalho e a formação recente têm sido evidenciadas.

$\mathrm{Na}$ maioria das falas dos sujeitos do estudo, os campos da promoção da saúde foram trans- 
versais, convergindo para as temáticas: a promoção da saúde associada à prevenção de agravos; a redução da promoção da saúde ao espaço escolar; a ausência da promoção da saúde para o adolescente no serviço; e a parceria como caminho da viabilização da promoção da saúde do adolescente.

\section{A promoção da saúde associada à prevenção de agravos}

No conjunto das falas dos participantes do estudo, observou-se recorrência, com ênfase na associação da promoção da saúde à prevenção de agravo, que caracteriza a vulnerabilidade do grupo adolescente, a exemplo da gravidez e exposição às drogas. Para efeito ilustrativo, um gestor ressaltou que em relação à adolescente, há duas grandes preocupações, a sexualidade, sobretudo no caso da mulher pra evitar a gravidez não desejada e a questão das drogas, confirmado por uma enfermeira, responsável pela atenção à saúde, quando acentuou que as ações têm acarretado uma diminuição no indice de gravidez e na minha área a gente já tem notado que a gravidez na adolescência tem diminuído bastante.

Destaca-se a unidade perceptiva dos profissionais de como a promoção da saúde é assimilada com a conotação preventiva, acrescida das visões dos profissionais gestores e não gestores que convergem para o entendimento verticalizado das ações de saúde. O gestor relatou que houve um aumento muito grande da disponibilidade de preservativo, a prefeitura que nunca havia comprado, passou a comprar.

O que está posto demarca uma compreensão minimizada dos princípios da promoção da saúde, pois estes ensejam mudanças no modo de pensar e operar a produção em saúde ${ }^{1}$, merecendo uma discussão mais aprofundada acerca da compreensão expressa por esses agentes sobre a díade prevenção e promoção.

Para Sícoli e Nascimento ${ }^{20}$, promoção da saúde refere-se a um modelo de atenção que vai além da assistência médico - curativa, no qual a concepção de saúde é considerada como produção social, resultado de relações de naturezas distintas, ou seja, econômicas, políticas, organizacionais, ideológicas, culturais e cognitivas.

Nesta linha de raciocínio, considerando a conjuntura atual, marcada pelas desigualdades sociais, a promoção da saúde ressalta a importância dos determinantes sociais em busca de padrões de atenção que extrapolem o modelo dominante ${ }^{21}$.
No arcabouço teórico, a prevenção estrutura-se mediante a divulgação de informação científica e de recomendações normativas de mudanças de hábitos. Já a promoção extrapola a aplicação técnica e normativa, pois tem como fim o fortalecimento das capacidades individuais e coletivas para a apreensão e enfrentamento dos condicionantes, mediante a autonomia dos indivíduos para escolhas de atitudes saudáveis².

Ao se pensar em modelos explicativos para a associação da promoção da saúde à prevenção de doenças, uma das vertentes pode ser ancorada na formação e hegemonia do modelo biomédico, que se encontra incorporado nos saberes e práticas dos profissionais de saúde.

\section{Redução da promoção da saúde ao espaço escolar}

Nas falas dos agentes, emergiram os limites imputados à prática de ações promotoras de saúde do adolescente ao espaço escolar. Mencionarem este ambiente como específico e prioritário, justificado por um gestor que não há como você fazer politica com adolescente que não seja dentro da escola.

A agregação da escola como locus privilegiado para a promoção da saúde do adolescente é uma elaboração subscrita no imaginário do profissional enfermeiro: a gente vai para as escolas, faz grupo com esses adolescentes, aborda a questão sexual, a questão da saúde bucal, vacinas, planejamento familiar. Esta perspectiva reafirmase quando os médicos condicionam a concretude dessas ações às demandas oriundas do próprio espaço escolar e foi sinalizado por um médico o modo como estas ocorrem: é mais quando eles procuram e a gente já fez ações pontuais nas escolas. Estes médicos reconhecem a desarticulação e a descontinuidade dessas ações e asseguram que estão fazendo palestras dentro dos colégios; aquela coisa bem pontual. A gente faz a palestra, passa um tempo, depois faz de novo com outra turma.

A cristalização do ideário associativo entre o adolescente, a escola e a promoção da saúde permeou a maioria das falas dos sujeitos desta pesquisa, ora acreditando que a efetivação do Programa Saúde na Escola será um diferencial para o alcance do coletivo escolar, no que diz respeito à manutenção e à busca por saúde, ora lamentando as dificuldades que desafiam a apreensão e a efetivação dos pressupostos da Política de Promoção da Saúde, mas ressurgindo esperanças no programa do Governo Federal. As for- 
mulações textuais de profissionais médicos corroboram a descrição: Existe até na prefeitura, eu acho, um trabalho do governo federal, o PSE, então isso ai eu acho que vai ajudar bastante a agente trabalhar mais com adolescente. A aposta que se está fazendo realmente é o Programa Saúde Escolar, a gente vai conseguir romper essas dificuldades e avançar, ter um diálogo.

Entender que ações de promoção da saúde direcionadas ao adolescente tenham a escola como um campo prioritário pode ser um fator limitante da atuação dos profissionais de saúde em outros contextos políticos e sociais. No seu escopo de trabalho, a promoção da saúde reconhece que decisões políticas de setores diferentes têm intensas repercussões sobre a saúde da população. Assim, ao se articular com outros campos, a saúde pode contribuir na elaboração de políticas públicas saudáveis focadas no adolescente ${ }^{22}$.

É imperioso ressaltar a ruptura da oralidade constituída pelos profissionais na fala de uma enfermeira, que revelou singularidades da escola, assinalando que não é fácil e tampouco receptiva ao diálogo sobre possibilidades de se promover saúde: na escola? Pense, na dificuldade para tentar passar alguma mensagem!

A escola é reconhecida como contexto privilegiado para efetivar ações de promoção da saúde, pois, dada a sua capilaridade e abrangência, é uma aliada importante para a concretização de ações de promoção da saúde, voltadas para o fortalecimento das capacidades dos indivíduos, para a tomada de decisão favorável à sua saúde e à comunidade, para a criação de ambientes saudáveis e promotores de saúde, bem como para a consolidação de uma política intersetorial, voltada para a qualidade de vida, pactuada no respeito ao indivíduo e tendo como foco o estabelecimento de uma nova cultura de saúde ${ }^{23}$.

A acepção dos profissionais, no entanto, não pode ser reduzida à realidade anunciada pelos sujeitos do estudo, que, desta forma, correm o risco de perder outros espaços potenciais ao desenvolvimento ou ao fomento de ações promotoras de saúde. A Política de Promoção da Saúde ${ }^{1}$ anuncia que esta se materializa na articulação sujeito/coletivo, público/privado, estado/sociedade, clínica/política, setor sanitário/outros setores, visando a romper com a excessiva fragmentação do processo/adoecimento e reduzir a vulnerabilidade, os riscos e os danos que nele se produzem.

Infere-se que a visão expressa pelos sujeitos pode estar associada aos próprios modelos de organização dos serviços de saúde, não estruturados de modo a acolher o adolescente, conside- rando-se a partir de suas necessidades e realidades que movem esse grupo a constantes desafios e empreendimentos.

Para ilustrar, um gestor justificou a ausência de adolescentes dos serviços de saúde e foi enfático, ao lamentar que as unidades tenham um perfil materno-infantil, não atrai adolescente, nem jovem.

Reafirmando o entendimento do gestor, a literatura sinaliza para o fato de programas voltados à saúde do adolescente requererem, efetivamente, a consideração das dimensões social e coletiva, abordadas de forma multiprofissional e interdisciplinar, envolvendo os diferentes aspectos que interagem no cotidiano dos adolescentes e no âmbito onde se encontram, procurando adaptar os conteúdos desses programas às diferentes modalidades de demandas individuais e coletivas, como aponta o estudo de Formigli et al. ${ }^{24}$, realizado há mais de uma década.

Ao incluir o adolescente em programas normatizados dos serviços de saúde, como referido pelo gestor, perpetua-se o paradigma biologicista, desconsideram a vivência e a significação dos processos de formação dos sujeitos em geral, tratando-se, de forma homogênea, as questões que envolvem um determinado grupo de pessoas, neste caso, o adolescente ${ }^{25}$.

Chama atenção nas falas dos entrevistados a transferência das ações de promoção de saúde do adolescente para o âmbito escolar, uma vez que não se tem no locus objeto de investigação programas consolidados com essas atribuições desenvolvidas nas instituições educacionais.

\section{Ausência da promoção da saúde para adolescentes no serviço}

Foi inegável no discurso dos participantes o fato de que a política de promoção da saúde ainda se apresenta de modo incipiente, em relação às especificidades da fase adolescente. A fala da enfermeira configura esta descrição: não é realizada nenhuma atividade de promoção da saúde exclusivamente para adolescentes, estas ações estão dentro do programa saúde da mulher, no pré-natal e planejamento familiar.

Apesar de a política de promoção da saúde não privilegiar o adolescente em suas especificidades, esta destaca a possibilidade de que os serviços de saúde reorientem suas práticas em direção às ações coletivas, que favoreçam o "empoderamento" individual e comunitário. Sob tal aspecto, é imperioso que seja conferida competência aos profissionais de saúde para lidarem com este público-alvo. 
Percebem-se, no entanto, com base nas evidências do estudo, dificuldades na priorização de ações para o adolescente. Estes são incluídos apenas nas atividades programadas nas unidades de saúde, caracterizando a dificuldade de reorientar a lógica da atenção, como sugerida na Carta de Ottawa ${ }^{17}$.

A literatura reforça um despreparo dos serviços de saúde em relação às práticas de cuidado com adolescentes, de forma a atender as peculiaridades e complexidades, faltando espaços e suporte apropriados às suas demandas, seja no campo da orientação, proteção ou recuperação da saúde ${ }^{26}$, e assim percebido por um gestor: $a$ unidade não é amigável do ponto de vista de atrair adolescente, de ser um espaço realmente de confiança e nem os profissionais se sentem preparados, principalmente para realizarem educação em saúde, pois estas ainda são pontuais.

Alguns profissionais têm visão ampliada de como concretizar a promoção da saúde com os adolescentes, valorizando a intersetorialidade e percebendo que o setor saúde não abarca as demandas, e reconhecem o papel da educação como articulador no alcance de experiências exitosas que promovam a saúde do adolescente. Para ilustrar, o gestor exprime: Eu vejo que a implementação da política não pode ser tratada somente dentro do centro de saúde, tem que envolver a educação, não há como você fazer política com adolescente que não seja dentro da escola, mas a gente barra pela formação dos professores que não conseguem dialogar sobre questões como sexo, gravidez, eles têm muitas dificuldades.

Desse modo, um desafio está expresso para os profissionais de saúde, no exercício da gestão e atenção, ao fomento de estratégias que sejam capazes de tornar o adolescente protagonista de sua própria saúde. Isto se concretiza, mediante a concessão de autonomia, responsabilização pessoal e social, motivação para o empreendedorismo, inclusão do adolescente na ideação, produção e valorização da arte, cultura, dos modos de brincar e se perceber como sujeito de direitos.

As práticas em saúde se encontram em transição e almejam cumprir os princípios da integralidade, priorizando a universalização da assistência nos níveis da promoção, proteção, recuperação e reabilitação. Corroborando esta asserção, Andrade e Bógus ${ }^{22}$ expressaram que esta transição implica um desafio constante de desconstituição de aspectos dos jovens dados como homogêneos e independentes do contexto em que estejam imersos.

\section{A parceria como caminho da viabilização da promoção da saúde do adolescente}

Na ideia da promoção da saúde, dentre os elementos a serem observados para a efetivação da política, destacam-se as parcerias, as quais devem ultrapassar os muros das unidades de saúde e atingir um contexto histórico, social, cultural, político e econômico dos indivíduos e coletividades. Esta realidade configura-se na visão dos gestores, ao afirmarem que essa parceria acontece especificamente no nível operacional quando é pactuado por gestores de secretarias distintas, por exemplo, na área de esporte e lazer.

Uma das opções apontadas pelas enfermeiras para o desenvolvimento de ações de promoção da saúde do adolescente foi à parceria com as escolas, que para estes profissionais contribuem significativamente para o desenvolvimento dessas ações no âmbito do serviço.

Esta visão expressa pelo grupo entrevistado sustenta-se nos princípios da Política Nacional de Promoção da Saúde, quando propõe que as intervenções em saúde sejam ampliadas, tomando como objeto os problemas, as necessidades, os determinantes e os condicionantes de saúde. Para tal, a organização da atenção e do cuidado deve criar mecanismos de mobilização e participação com os vários movimentos e grupos sociais, por intermédio do estabelecimento de parcerias, pois as atuações isoladas não são suficientes para lidar com a complexidade das questões de saúde-doença-cuidado ${ }^{1}$.

Percebe-se uma ênfase nos recortes estudados, apontando a escola como um locus privilegiado para o desenvolvimento de ações de promoção da saúde para o adolescente.

Outros espaços configuram-se como cenários para essas práticas. Esta asserção sustenta-se nos estudos que apontam a indústria, a igreja, o núcleo de ação social e o Núcleo de Apoio a Saúde da Família (NASF) como espaços de parcerias com o serviço de saúde ${ }^{27,28}$.

Este aspecto foi destacado por enfermeiros e dentistas, quando referiram que o NASF também está inserido no atendimento ao adolescente, com profissionais diversos, fonoaudiólogo, fisioterapeuta, nutricionista e educador físico que trabalham de uma forma interdisciplinar.

A visão limitada dos profissionais no estabelecimento de parcerias com outros cenários, além da escola, representa um desafio a ser superado para concretizar a promoção da saúde do adolescente, vislumbrando a intersetorialidade como instrumento de criação dos espaços comunicati- 
vos que possibilitem a resolução de problemas complexos, corroborando Silva e Rodrigues ${ }^{27}$, que apontam a intersetorialidade como uma estratégia inovadora ainda em construção, cujos caminhos estão sendo desvendados.

Chama-se a atenção para a ênfase na formação dos profissionais de saúde, destacada nos depoimentos, em que a maioria dos sujeitos ressalta a necessidade de capacitações, além de falhas na formação acadêmica, para que possam atender de modo mais dinâmico e efetivo as necessidades dos adolescentes. Observa-se que os profissionais se referem ao termo capacitação, que traz uma abordagem, na maioria dos casos, pautada na transmissão de conhecimentos referendados nas razões do "modelo escolar", com o intuito de atualizar novos enfoques, novas informações ou tecnologias na implantação de uma política.

Apesar das evidências, insiste-se no estilo de capacitação que demonstra ser a lógica escolar incorporada habitual e sutilmente nos modelos mentais. Ainda que em alguns casos se alcancem aprendizagens individuais por meio da capacitação, elas nem sempre se traduzem em aprendizagem organizacional ${ }^{29}$; isto é, não se transferem para a ação coletiva.

A Política Nacional de Educação Permanente em Saúde ${ }^{29}$ rompe com essa ideia, quando propõe um aperfeiçoamento profissional pautado na realidade encontrada nos serviços de saúde e em seus conhecimentos prévios, aproximando a teoria da prática.

O depoimento dos gestores também aponta para esta evidência, destacando a influência do processo de formação, em que alguns profissionais se identificam mais do que outros para promover a saúde de adolescentes na atenção básica, além de enfatizar o fato de que, para sanar esta dificuldade, promove amostras de iniciativas de promoção da saúde que estão dando certo, mas que são fragmentadas e descontextualizadas.

Outro aspecto referido por médico e dentista é que os adolescentes não procuram a unidade, nós é que temos que ir atrás deles. Este achado não difere de pesquisa realizada ${ }^{27,28}$, em que profissionais trabalhadores que atuam em programas de atenção à saúde de adolescentes referem dificuldades no trato diário com esse grupo etário, pois, para que se cumpra a agenda de atividades, os esforços parecem ser em vão, causando-lhes frustração, desmotivação, mal-estar e até mesmo irritação, pois geralmente não comparecem ao serviço.

A captação dos adolescentes deve ser realizada por meio de ações estratégicas, tanto nas uni- dades de saúde quanto na comunidade. A atenção à saúde destes não deve se limitar às atividades realizadas no âmbito da unidade de saúde. É importante, no entanto, o profissional de saúde otimizar as oportunidades de contato com os adolescentes $^{30}$.

Para a adesão do adolescente ao espaço que lhe é oferecido, é necessário permitir que ele seja ouvido, possa expor suas ideias, sentimentos e experiências, e que também seja respeitado e valorizado. O adolescente não quer nada pronto e, talvez, ele ainda não tenha encontrado este espaço no serviço de saúde ${ }^{25}$.

Quando os profissionais conquistam a confiança dos adolescentes, eles se tornam ouvintes e interlocutores, mas, antes mesmo que aconteça esta interação, é necessário que se efetive uma política pública para ampliar o acesso deles aos serviços de saúde. Os espaços criados para discussão e aprofundamento de questões formuladas pelos próprios viabilizam o empowerment destes, como enfatiza o terceiro campo da Carta de Ottawa - Reforço da Ação Comunitária ${ }^{17}$.

Os profissionais que exercem função como de gestores destacaram a importância das parcerias: os adolescentes não podem ser tratados somente dentro do centro de saúde. E acrescentaram que no nível da gestão a garantia deste trabalho intersetorial, muitas vezes, não acontece na prática, além de algumas dificuldades técnicas dos profissionais de outros setores em abordar questões específicas da saúde. Em decorrência da adesão do Programa Saúde na Escola (PSE), evidenciando que é impossível realizar ações de Promoção da Saúde para os adolescentes só no interior das unidades de saúde, esta adesão poderá facilitar a multidisciplinaridade caracterizada na fala dos profissionais pelo trabalho com o Núcleo de Apoio à Saúde da Família (NASF), além da utilização de potenciais da comunidade, como a parceria relatada com uma instituição presente na área.

A escola constitui ambiente favorável ao desenvolvimento humano, e se apresenta como parceira importante para o setor saúde e comunidade, no sentido de reforçar as condições necessárias para a Promoção da Saúde do adolescente com a inclusão de vários temas da saúde no currículo e no cotidiano escolar, porque se constitui um ambiente que amplia as oportunidades de acesso a atividades educativas, culturais, esportivas, de lazer e de geração de renda, além do exercício da cidadania.

O Ministério da Saúde lançou o Programa Saúde na Escola (PSE), por meio do decreto $\mathrm{n}^{\circ}$ 
6.286, de 5 de dezembro de 2007, que tem por objetivo contribuir para a formação integral dos estudantes da rede pública de educação básica mediante ações de prevenção, promoção e atenção à saúde ${ }^{31}$. Para tanto, estabeleceu-se incentivo financeiro pela adesão ao PSE para os municípios com Equipes de Saúde da Família, priorizados com o Índice de Desenvolvimento de Educação Básica (IDEB), cobertura da Estratégia Saúde da Família e aqueles inseridos no Programa Mais Educação, conforme nova portaria PT $\mathrm{n}^{\circ}$ 3146 de $17 / 12 / 09^{32}$.

No Município de Fortaleza, o PSE está presente em 42 escolas municipais, que são privilegiados pelo programa Mais Educação e em 19 centros de saúde. Atualmente as ESF estão, em parceria com diretores das escolas, finalizando o plano de ação para implantação do PSE a partir do segundo semestre de 2010.

Durante as discussões acerca dos fatores facilitadores para realizar ações de Promoção da Saúde, o pronunciamento dos profissionais voltou-se para a disponibilidade da equipe de profissionais, as ações intersetoriais, por meio dos NASF e das parcerias, configurando, assim, a reorientação de serviços preconizada na Carta de Ottawa.

Em relação às mudanças ocorridas após a implementação das ações de Promoção da Saúde no contexto estudado, pensa-se que a falta de percepção de mudanças sucede pelos dois aspectos sinalizados nas falas, quer seja ausência de avaliação, que configure evidências de mudanças, bem como sistematização das ações, que possibilite acompanhar este processo.

Verificou-se que as mudanças percebidas se referem essencialmente a ações voltadas apenas para a saúde das adolescentes, ou seja, para o planejamento familiar e pré-natal, que já são programas exercidos dentro do cronograma diário destes profissionais, o que reforça a falta de ações que priorizem a integralidade na atenção ao adolescente.

Neste sentido, elucida-se a importância da participação de adolescentes nos grupos de educação em saúde, pois estes proporcionam e sinalizam o "empoderamento" com foco para prevenção de agravos e discussão de temas, como gravidez na adolescência, aborto, DST, métodos contraceptivos, alimentação saudável, higienização, cidadania e saúde bucal. Enfatiza-se o reforço da ação comunitária da Carta de Ottawa, que preconiza o envolvimento da comunidade na discussão e avaliação dos problemas para viabilizar o "empowerment" desta ${ }^{17}$. Nesta perspectiva de análise, pode-se inferir que a abordagem aos ado- lescentes necessita ser ampliada para outros contextos, como cidadania, projetos de vida, realização de sonhos, incentivo à autoestima, participação juvenil e voluntariado, relações de gênero, relacionamentos sociais, cuidado com o corpo, autocuidado e autoconhecimento, uso de álcool, tabaco e outras drogas, violência doméstica e social, cultura de paz, esportes, trabalho, dentre outros temas de interesse dos adolescentes.

Constata-se, portanto, uma lacuna neste contexto, no que se refere à avaliação das práticas realizadas pelos profissionais junto aos adolescentes. Entende-se que a avaliação se faz necessária em todos os processos de trabalho: primeiro, por possibilitar um monitoramento, e, segundo, para sinalizar mudanças rumo às práticas mais efetivas.

\section{Considerações finais}

Os sentidos atribuídos, pelos profissionais, à promoção da saúde do adolescente apontaram para: a prevenção de agravos; a redução ao espaço escolar; a ausência nos serviços de saúde; e a parceria para viabilizar as ações.

A promoção da saúde para adolescentes na Estratégia Saúde da Família sob a óptica dos profissionais foi considerada incipiente, o que certamente compromete a saúde e a utilização do serviço por esta clientela.

Perceberam-se, no entanto, iniciativas para promover a saúde dos adolescentes, o que se configurou como atividades educativas realizadas de forma contingencial e ainda centradas na informação, sinalizando para um trabalho interdisciplinar, mais especificamente nas instituições escolares e associações.

Com a implementação do Programa Saúde na Escola, acredita-se em mudanças, constituindo-se um novo panorama de assistência, com qualidade, para os adolescentes. Confirmou-se, porém, nos achados, a falta de movimentos políticos que estimulem o interesse e a participação dos profissionais da ESF pela promoção da saúde junto aos adolescentes.

O destaque às parcerias foi elucidado como caminho para viabilizar a promoção da saúde do adolescente, com o realce de que estas devem ultrapassar os muros das unidades de saúde e atingir um contexto histórico, social, cultural, político e econômico dos indivíduos e coletividades.

Destaca-se como limitação nesse estudo a identificação dos gestores que poderiam exercer governabilidade sobre a questão dos adolescen- 
tes, porém a maioria demonstrou dificuldades em falar sobre a política municipal para este grupo de usuário do serviço público de saúde.

Na perspectiva da promoção da saúde, compreende-se que este estudo possa contribuir para a reflexão dos gestores e profissionais da equipe da ESF, com vista a subsidiar a aplicação das políticas públicas para o adolescente. Avançar neste tipo de assistência e alcançar uma atenção integral à saúde, como preconizado na legislação, é caminhar sempre para uma ação equânime, resolutiva, de qualidade e humanizada.

\section{Colaboradores}

AAG Santos, RM Silva, MFAS Machado participaram da elaboração e desenvolvimento da pesquisa; LJES Vieira, AMF Catrib, HMF Jorge participaram da análise dos dados e da redação do artigo.

\section{Agradecimentos}

À FUNCAP, pelo apoio financeiro ao projeto e bolsa de iniciação científica, e ao CNPq pelo incentivo à bolsa de produtividade em pesquisa $\mathrm{e}$ de iniciação científica.

\section{Referências}

1. Brasil. Ministério da Saúde (MS). Secretaria de Vigilância em Saúde. Política nacional de promoção da saúde. Brasília: MS; 2006.

2. Czeresnia D, Freitas CM, organizadores. Promoção da saúde: conceitos, reflexões, tendências. Rio de Janeiro: Fiocruz; 2003. p. 176.

3. Cerqueira MT. Promoción de la salud: evolución y nuevos rumbos. Boletin de la Oficina Sanitaria Panamericana. Cien Saude Colet 1996; 120(23):342-347.

4. Campos GWS. Análise crítica das contribuições da saúde coletiva à organização das práticas de saúde no SUS. São Paulo: Lemos; 1997.

5. Njaine K. Sentidos da violência ou a violência sem sentido: o olhar dos adolescentes sobre a mídia, Brasil. Interface Comunic Saúde Educ 2006; 20(10):381392.

6. Gurgel MGI, Alves MDS, Vieira NFC, Pinheiro PNC, Barroso GT. Gravidez na adolescência: tendência na produção científica de enfermagem. Rev Esc. Anna Nery 2008; 12(4):800-804.

7. Bretas JRS, Ohara CVS, Jardim DP, Muroya, RL. Conhecimento sobre DST/AIDS por estudantes adolescentes. Rev esc. enferm USP 2009; 43(3):551-557.

8. Brasil. Ministério da Saúde (MS). Secretaria executiva. Coordenação da saúde da criança e do adolescente. Programa saúde do adolescente. Bases programáticas. 2a ed. Brasília: MS; 1996.

9. Buss PM. Uma introdução ao conceito de promoção da saúde. In: Czeresnia D, Freitas CM, organizadores. Promoção da saúde: conceitos, reflexões, tendências. Rio de Janeiro: Fundação Oswaldo Cruz; 2003.

10. Minayo MCS. O desafio do conhecimento: pesquisa qualitativa em saúde. $10^{\text {a }}$ ed. São Paulo: Hucitec; 2010 . 
11. Vieira LJES, Carneiro RCMM, Frota MA, Gomes LA, Ximenes LB. Ações e possibilidades de prevenção de acidentes com crianças em creches de Fortaleza, Ceará. Cien Saude Colet 2009; 14(5):1687-1697.

12. Fortaleza. Prefeitura Municipal. Secretaria Municipal de Saúde. Relatório de Gestão 2005-2006. Saúde, Qualidade de Vida e a ética do cuidado. Fortaleza: Imprensa Municipal; 2007.

13. Monteiro MM, Figueiredo VP, Machado MFAS. Formação do vínculo na implantação do Programa Saúde da Família numa Unidade Básica de Saúde. Rev. esc. enferm USP 2009; 43(2):358-364.

14. Brasil. Ministério da Saúde. Portaria n ${ }^{\circ}$. 648. Aprova a política nacional de atenção básica, estabelecendo a revisão de diretrizes e normas para organização da Atenção Básica para o Programa Saúde da Família (PSF) e o Programa Agentes Comunitários de Saúde (PACS). Diário Oficial da União 2006; 28 mar.

15. Bardin L. Análise de conteúdo. Lisboa: Edições 70; 2008.

16. Deslandes SF, Gomes R, Minayo MCS. Teoria, método e criatividade. 26a ed. Rio de Janeiro: Vozes; 2007.

17. Brasil. Ministério da saúde (MS). As cartas da promoção da saúde. Brasília: MS; 2002.

18. Brasil. Conselho Nacional de Saúde. Resolução 196/ 96. Decreto no 93.993, de Janeiro de 1987. Estabelece critério sobre pesquisas envolvendo seres humanos. Brasília: Bioética; 1996.

19. Luna GLM, Ferreira RC, Vieira LJES. Notificação de maus-tratos em crianças e adolescentes por profissionais da Equipe Saúde da Família. Cien Saude Colet 2010; 15(2):481-491.

20. Sícoli JL, Nascimento PR. Health promotion: concepts, principles and practice. Interface Comunic Saúde Educ 2003; 12(7):91-112.

21. Silva JGE, Gurgel AA, Frota MA, Vieira LJES, Valdés MTM. Promoção da saúde: possibilidades de superação das desigualdades sociais. Rev Enfermagem (UERJ) 2008; 16(3):421-425.

22. Andrade EA, Bógus CM. Public policies targeted at youth and health promotion: how the proposal for youth auxiliaries has been translated into practice. Interface Comunic Saúde Educ 2010; 35(14):853-866.

23. Brasil. Ministério da Saúde. Secretaria de Políticas de Saúde. A promoção da saúde no contexto escolar. Rev Saude Publica 2002; 36(4):533-535.

24. Formigli VLA, Costa COM, Porto LA. Avaliação de um serviço de atenção integral à saúde do adolescente. Cad Saude Publica 2000; 16(3):831-841.
25. Fonseca DC, Ozella S. The conceptualizations of adolescence constructed by professionals within the Family Health Strategy (FHS). Interface Comun Saúde Educ 2010; 33(14):411-424.

26. Queiroz MVO, Ribeiro EMV, Pennafort VPS. Assistência ao adolescente em um serviço terciário: acesso, acolhimento e satisfação na produção do cuidado. Rev Texto Contexto Enferm 2010; 19(2):291-299.

27. Silva KL, Rodrigues AT. Ações intersetoriais para promoção da saúde na Estratégia Saúde da Família: experiências, desafios e possibilidades. Rev. Bras. Enferm 2010; 63(5):762-769.

28. Guedes LE, Ferreira JM. Relações disciplinares em um centro de ensino e pesquisa em práticas de promoção da saúde e prevenção de doenças. Rev Saude Soc 2010; 19(2):260-272.

29. Brasil. Ministério da Saúde. Secretaria de gestão do trabalho e da educação na saúde. Departamento de gestão da educação em saúde. Política Nacional de Educação Permanente em Saúde. Ministério da Saúde, Secretaria de Gestão do Trabalho e da Educação na Saúde, Departamento de Gestão da Educação em Saúde. Brasília: MS; 2009.

30. Ferrari RAP, Thomson Z, Melchior R. Atenção à saúde dos adolescentes: percepção dos médicos e enfermeiros das equipes da saúde da família. Cad Saude Publica 2006; 22(11):2491-2495.

31. Brasil. Ministério da Saúde. Decreto no 6.286, de 5 de dezembro de 2007. Institui o programa saúde na escola e dá outras providências. Diário Oficial da União 2007; 5 dez.

32. Brasil. Ministério da Saúde (MS). Secretaria de atenção à saúde. Saúde integral de adolescentes e jovens: orientações para a organização de serviços de saúde. Brasília (DF): MS; 2005. [Série A. Normas e Manuais Técnicos].

Artigo apresentado em 17/03/2011

Aprovado em 12/07/2011

Versão final apresentada em 05/08/2011 